\title{
Osteoporotic Compression Fracture of Spine Treated With Posterior Instrumentation and Transpedicular Bone Grafting
}

\author{
Foead Al, MS Orth, Thanapipatsiri S*, MD, Pichaisak W*, MD, Varmvanij V*, MD \\ Department of Orthopaedic Surgery, Hospital Tuanku Ampuan Najihah, Kuala Pilah, Malaysia \\ *Department of Orthopaedic Surgery, Siriraj Hospital, Bangkok, Thailand
}

\begin{abstract}
A series of 11 patients with osteoporotic compression fracture of the spine who underwent posterior instrumentation and transpedicular bone drafting in Siriraj Hospital Bangkok was analysed retrospectively. The indications for surgery were neurological deficit, kyphotic deformity and intractable pain. The mean follow up period was 10.1 months (range, $2.1-25.5$ months). On follow up, all patients indicated recovery from pain. Most patients (7/11) regained one Frankel grade and one patient who was Frankel grade D preoperatively remained grade D postoperatively. Daily functionality improved in nine patients, but two patients still required aid for walking and standing. There was no pedicle screw loosening, pull-out or implant breakage as of the last date of follow up. Adjacent vertebrae also did not show any fracture or reduction in height. We conclude that this operative method is acceptable for osteoporotic fracture of the spine, although a longer period of follow up is needed to further evaluate its efficacy.
\end{abstract}

\section{INTRODUCTION}

Osteoporotic fractures of the spine often cause significant morbidity in the elderly. Detailed history, physical examination and magnetic resonance imaging (MRI) are usually required to exclude other causes of back pain ${ }^{1,2}$. Treatment of osteoporotic fracture of spine can be perplexing.

Vertebral augmentation procedures such as vertebroplasty or kyphoplasty have replaced traditional conservative management. Typically, those patients who present with neurological deficit will require open surgery ${ }^{1,2}$. Various methods have been described in the literature, such as: anterior corpectomy with interbody fusion and anterior instrumentation; posterior instrumentation enhanced by pedicle screws and rods and transpedicular bone grafting; or two-step procedures such as posterior stabilisation enhanced by pedicle screws and rods, followed by anterior corpectomy with interbody fusion ${ }^{3}$. No matter which methods are used, fixation of osteoporotic spine has a relatively high failure rate of $20 \%{ }^{3}$. This is a retrospective study to show preliminary result of posterior instrumentation augmented with pedicle screws, rods, and transpedicular bone grafting.

\section{MATERIALS AND METHODS}

The author performed this study during his spinal surgery fellowship training in Siriraj Hospital, Bangkok, Thailand. It includes patients with osteoporotic compression fracture of spine, who were admitted to Department of Orthopaedic Surgery at Siriraj Hospital from October 1, 2001 to June 30, 2004. All patients were treated with posterior instrumentation and transpedicular bone grafting. The clinical record was reviewed for demographic data, injury mechanism, operative time, intraoperative blood loss, neurological improvement and complications. All patients were diagnosed with primary osteoporosis. The main indications for surgery were progressive neurological deficit, kyphotic deformity and intractable pain. The decision to use this procedure was based the desire to improve the general well being, condition of the fracture and surgeon's preference. Informed consent was obtained for all cases.

The common posterior approach to the thoracolumbar spine was utilised in all cases. Patients were positioned prone on a four-post (Relton-Hall) frame or between two bolsters. Since the kyphotic deformities of osteoporotic fractures are usually flexible, positioning in this manner helps in part to reduce or realign to normal sagittal alignment. Skin disinfection and draping was done in the usual manner. A longitudinal midline skin incision was made over the pathological vertebrae extending two levels above and two levels below. Care was taken not to disrupt the facet joint capsules. The fracture site was reconfirmed with fluoroscopy. Pedicle screws of adequate size were inserted two levels above and two levels below to bridge the fracture, with pedicles tapped only at their outer cortices. Cancellous bone was not tapped to increase pullout strength of the screws. Decompression laminectomy was performed at the fracture level. Pedicles of the fracture site were probed with a blunt pedicle finder. A small angled curette was inserted to curette out fibrous tissue, so as to widen the space inside the fractured body. 
Caution was used when curetting through the pedicle to avoid cortical breakage or pushing beyond the anterior longitudinal ligament. Cancellous bone graft from the iliac crest was harvested and chipped into small pieces. The Synthes ${ }^{\circledR}$ bone graft funnel was inserted into the pedicle, and chipped bone graft was slowly pushed and tamped into the body, gradually restoring the height of the fractured vertebra, hence improving the kyphotic deformity. Two rods of adequate length were cut, contoured and fixed with the pedicle screws. A Redivac drain was inserted prior to closure. Postoperatively patients prescribed lumbar orthosis for three months. Patients were discharged from hospital about seven to 10 days postoperatively. Follow up took place in outpatient clinic after one, three, six, and twelve months and every twelve months thereafter.

\section{RESULTS}

Patient characteristics are shown in Table I. The study consisted of review of 10 women and one man chosen for this procedure. In addition to kyphotic deformity, eight patients had neurological deficit and 3 had intractable pain. The mean age was 72.6 years (range $58-85$ years). The fractures were mostly located at the thoracolumbar junction. All fractures were caused by a slip and fall at home. The average time from injury to admission was 3.9 months (range 0.3 - 21 months), and the average follow up was 10.1 months (range 2.1 - 25.5 months). The male patient had hemiparesis 15 years prior to the injury due to stroke and had been able walk with the aid of walker. He developed cauda equina syndrome after traditional massage. The mean operative time was 169.5 minutes (range 150 - 240 minutes) and mean estimated blood loss was $468 \mathrm{~mL}$ (range $200-$ $1500 \mathrm{~mL})$.

Neurological status of the patients is shown in Table II. Preoperatively, four patients had Frankel grade C, four had grade D, and three had grade E function. Postoperatively, most patients improved one grade in function on the Frankel scale, but one patient remained to have Frankel at grade D after surgery. At the date of last follow up, the patient with cauda equina syndrome had regained his sphincter control postoperatively. One woman who lost her sphincter control preoperatively did not regain her sphincter control postoperatively.

Three patients who had severe pain recovered fully by the time of this review. In this study, we did not grade the pain with a specific scoring system. We only recorded the subjective feeling as how it was felt by the patients as noted the medical record. Functionality in terms of the ability to sit, stand and walk is shown in Table II. Two patients needed aid to stand and walk as of the last postoperative visit.

We measured the kyphotic angle on the lateral view plain radiograph using Cobb technique, from the superior endplate of one level above and the inferior endplate of one level below the fractured vertebra. The average preoperative kyphotic angle was $+30.11^{\circ}$ ( $31^{\circ}$ of kyphosis) (range, $+20-$ $+42^{\circ}$ ), and was corrected to an average of $+15.89^{\circ}$ (range, +4 - $\left.+37^{\circ}\right)$. The anterior vertebral height $50.17 \%$ (27.5 $84.4 \%)$ was corrected to $71.38 \%(51.7-100 \%)$. The average posterior vertebral height of $73.08 \%$ (range, $51.9-96.6 \%$ ) was corrected to $86.29 \%$ (range, $70.2-100 \%$ ).

\section{DISCUSSION}

As seen in the preceding section, posterior instrumentation and transpedicular bone grafting are reported to give satisfactory results in terms of pain relief, improvement in neurological status, and correction of the kyphotic deformity. Screw pull-out is a significant concern in osteoporotic patients. Loss of mineral content, thinning of trabeculae as well as enlargement of Haversian and marrow spaces in osteoporosis reduces structural strength of cancellous bone ${ }^{4}$. This factor as well as repetitive loading and micro-cracks of the cortices will cause pullout of the screw ${ }^{4}$.

We did not tap the cancellous matrix so that it could be compressed during screw insertion. This increases the density of bone between the screw threads, which in turn, increases the pullout resistance. Halvorson et al. ${ }^{5}$ and Benzel $^{6}$ demonstrated that tapping decreased pullout resistance in osteoporotic bone. The compressive effect of bone surrounding the screw enhances screw purchase, thus enhancing stabilisation of the spinal construct. We avoided excessive bending of the rod so as to create a splint for loadsharing of the spine. We also avoided rods that were too straight, for fear that cantilever force could pull out the pedicle screws ${ }^{7}$.

We prefer posterior instrumentation to anterior instrumentation and believe that a long rod and short fusion construct (load-sharing principle) ${ }^{9}$ was strong enough to stabilise the osteoporotic fracture. Moon et al. ${ }^{10}$ compared the effectiveness of long segment and short segment fixation in thoracic and lumbar fractures and reported that long and short rod fusion was more effective than the short rod and fusion construct, although it leads to wider immobilisation of normal segments. A biomechanical study by Chiba et al. ${ }^{11}$ and Hasegawa et $a l^{12}$ showed that the use of posterior short segment instrumentation with pedicle screws and augmentation with supra and infralaminar hooks resulted in increased stiffness compared to pedicle screws alone. However, we have not had any experience yet with the combination of pedicle screws, hooks and a short segment construct.

Transpedicular bone grafting was introduced by Daniaux ${ }^{8}$ in 1986 to achieve an interbody fusion. This method was also used by other authors ${ }^{13,14}$ to treat thoracolumbar fractures. However, in addition to posterior instrumentation, we 
Table I: Demographic data of the patients

\begin{tabular}{|c|c|c|c|c|c|c|}
\hline Case & Age (yr) & Sex & Fracture & Follow up & $\begin{array}{l}\text { Instrumentation } \\
\text { duration (months) }\end{array}$ & $\begin{array}{c}\text { Transpedicular } \\
\text { Bone graft }\end{array}$ \\
\hline 1 & 70 & $\mathrm{~F}$ & T12, old T10 & 4.8 & $\mathrm{~T} 9, \mathrm{~T} 11, \mathrm{~L} 1, \mathrm{~L} 2$ & $\mathrm{~T} 12$ \\
\hline 2 & 76 & $\mathrm{M}$ & L2 & 3.9 & $\mathrm{~T} 12, \mathrm{~L} 1, \mathrm{~L} 3, \mathrm{~L} 4$ & L2 \\
\hline 3 & 79 & $\mathrm{~F}$ & $\mathrm{~T} 12$ & 13.5 & $\mathrm{~T} 10, \mathrm{~T} 11, \mathrm{~L} 1, \mathrm{~L} 2$ & $\mathrm{~T} 12$ \\
\hline 4 & 67 & $\mathrm{~F}$ & T12, L1 & 10.3 & T9,T11,L2,L3 & $\mathrm{T} 12$ \\
\hline 5 & 58 & $\mathrm{~F}$ & $\mathrm{~T} 12$ & 2.1 & $\mathrm{~T} 10, \mathrm{~T} 11, \mathrm{~L} 1, \mathrm{~L} 2$ & $\mathrm{~T} 12$ \\
\hline 6 & 77 & $\mathrm{~F}$ & nonunion L1 & 22.3 & $\mathrm{~T} 11, \mathrm{~T} 12, \mathrm{~L} 2, \mathrm{~L} 3$ & L1 \\
\hline 7 & 67 & $\mathrm{~F}$ & nonunion T12 & 7.9 & $\mathrm{~T} 10, \mathrm{~T} 11, \mathrm{~L} 1, \mathrm{~L} 2$ & $\mathrm{~T} 12$ \\
\hline 8 & 85 & $\mathrm{~F}$ & T12 & 25.5 & $\mathrm{~T} 9, \mathrm{~T} 11, \mathrm{~L} 1, \mathrm{~L} 2$ & $\mathrm{~T} 12$ \\
\hline 9 & 70 & $\mathrm{~F}$ & nonunion T12 & 5.2 & $\mathrm{~T} 10, \mathrm{~T} 11, \mathrm{~L} 1, \mathrm{~L} 2$ & $\mathrm{~T} 12$ \\
\hline 10 & 74 & $\mathrm{~F}$ & $\mathrm{~T} 12$, nonunion L1 & 6.0 & $\mathrm{~T} 11, \mathrm{~T} 12, \mathrm{~L} 2, \mathrm{~L} 3$ & $\mathrm{~T} 12$ \\
\hline 11 & 76 & $\mathrm{~F}$ & L2 & 9.6 & $\mathrm{~T} 12, \mathrm{~L} 1, \mathrm{~L} 3, \mathrm{~L} 4$ & $\mathrm{~L} 2$ \\
\hline
\end{tabular}

Table II: Preoperative and postoperative neurological status and daily functionality of the patients in terms of sitting, standing and walking

\begin{tabular}{|c|c|c|c|c|c|c|c|c|c|c|}
\hline \multirow[t]{3}{*}{ Case } & \multicolumn{5}{|c|}{ Preoperative } & \multicolumn{5}{|c|}{ Postoperative } \\
\hline & \multicolumn{2}{|c|}{ Neurological status } & \multicolumn{3}{|c|}{ Daily functionality } & \multicolumn{2}{|c|}{ Neurological status } & \multicolumn{3}{|c|}{ Daily functionality } \\
\hline & $\begin{array}{l}\text { Frankel } \\
\text { grade }\end{array}$ & $\begin{array}{l}\text { Sphincter } \\
\text { control }\end{array}$ & Sitting & Standing & Walking & $\begin{array}{c}\text { Frankel } \\
\text { grade }\end{array}$ & $\begin{array}{l}\text { Sphincter } \\
\text { control }\end{array}$ & Sitting & Standing & Walking \\
\hline 1 & D & normal & support & unable & unable & $\mathrm{E}$ & normal & able & able & able \\
\hline 2 & $\mathrm{C}$ & loss & unable & unable & unable & $\mathrm{D}$ & normal & able & with aid & with aid \\
\hline 3 & $D$ & normal & support & unable & unable & $\mathrm{D}$ & normal & able & with aid & with aid \\
\hline 4 & $\mathrm{E}$ & normal & able & able & able & $E$ & normal & able & able & able \\
\hline 5 & C & loss & able & with aid & with aid & $D$ & loss & able & able & able \\
\hline 6 & $\mathrm{C}$ & normal & support & with aid & unable & $\mathrm{D}$ & normal & able & able & able \\
\hline 7 & $\mathrm{C}$ & normal & support & unable & unable & D & normal & able & able & able \\
\hline 8 & $D$ & normal & support & with aid & unable & $E$ & normal & able & able & able \\
\hline 9 & $D$ & normal & support & unable & unable & E & normal & able & able & able \\
\hline 10 & $\mathrm{E}$ & normal & able & able & able & $\mathrm{E}$ & normal & able & able & able \\
\hline 11 & $E$ & normal & able & able & able & $E$ & normal & able & able & able \\
\hline
\end{tabular}

Table III: Kyphotic angle, percentage of anterior and posterior vertebral body height at preoperative and the last follow up postoperative

\begin{tabular}{|lcc|}
\hline Mean & Preoperative & Postoperative \\
\hline Kyphotic angle (degree) & $30.11(20-42)$ & $15.89(4-37)$ \\
Anterior body height (\%) & $50.17(27.5-84.4)$ & $71.38(50-100)$ \\
Posterior body height (\%) & $73.08(51.9-96.6)$ & $86.29(70.2-100)$ \\
\hline
\end{tabular}
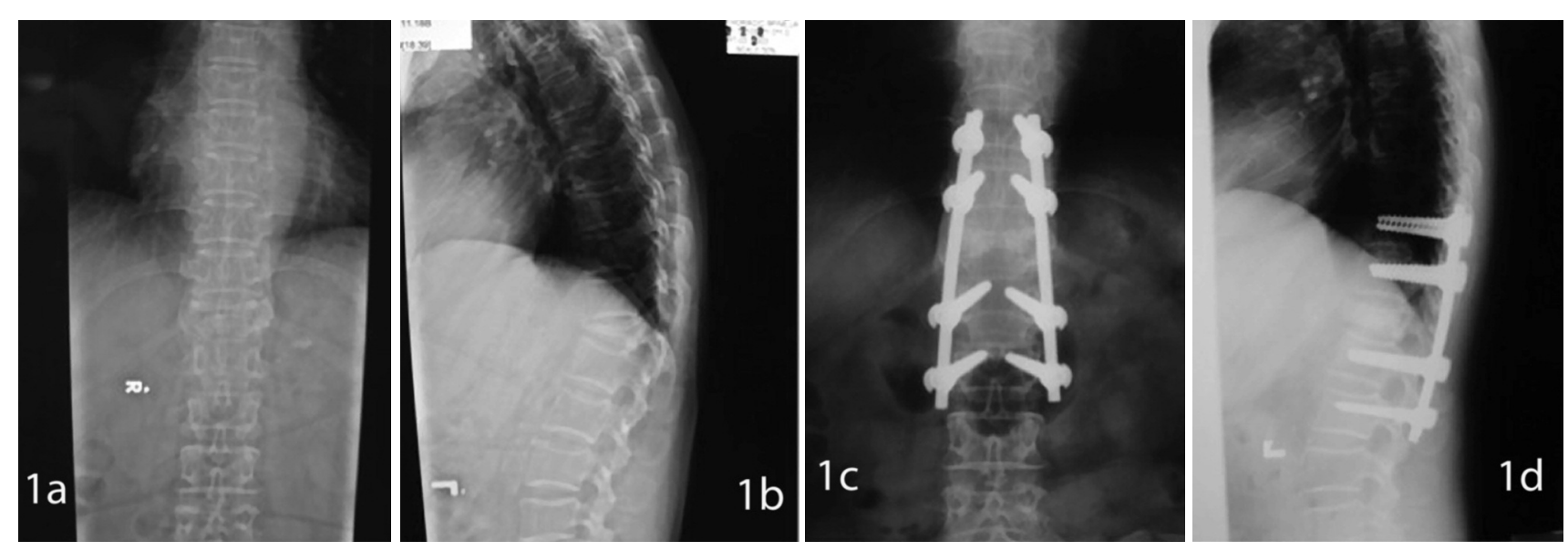

Fig. 1: Plain radiograph of Case 3. a. Pre-operative AP view, b. Pre-operative lateral view, c. Post-operative AP view, d. Post-operative lateral view. 

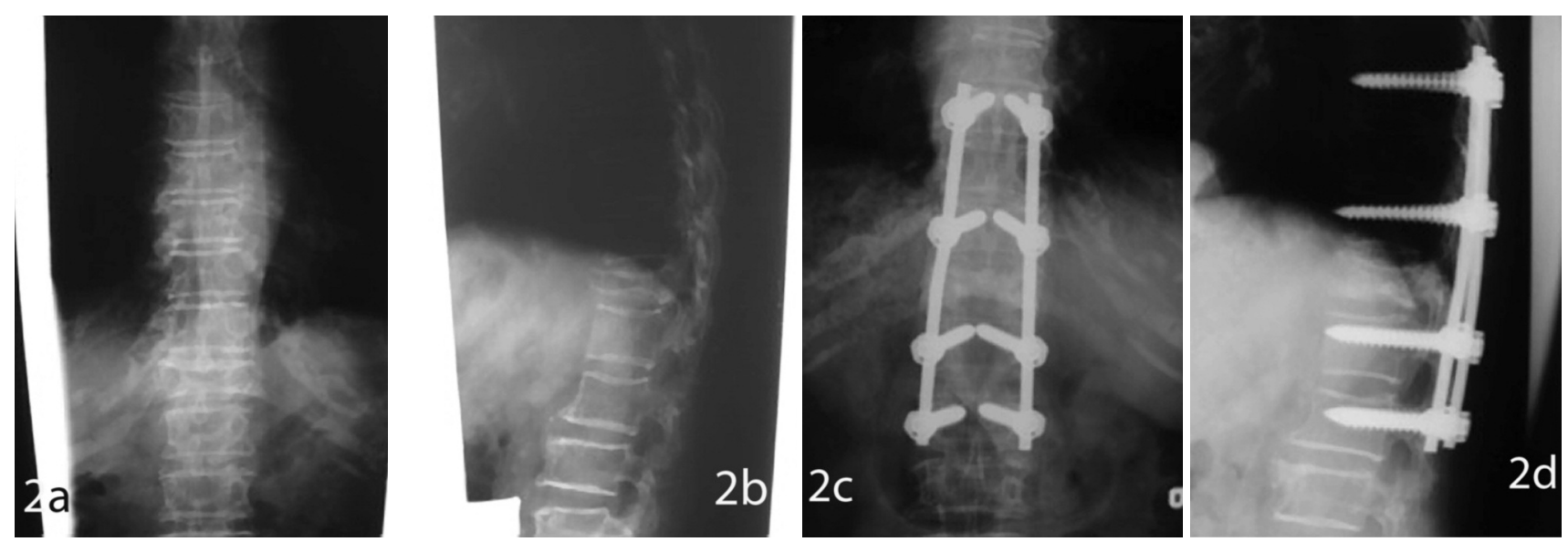

Fig. 2: Plain radiograph of Case 8. a. Pre-operative AP view, b. Pre-operative lateral view, c. Post-operative AP view, d. Post-operative lateral view.

adopted this method to re-establish the load-bearing-capable anterior column. Bone graft itself has the same Young's modulus rather than polymethylmetacrylate (PMMA), thus the risk of fracture at the vertebrae above and below the pathological vertebra is reduced ${ }^{15}$.

We prefer vertebroplasty or kyphoplasty in those whose general condition is frail or undernourished. Of note, venous embolism, pulmonary embolism or cement leakage after vertebroplasty is reported in $27.3 \%$ of acute stage patients ${ }^{16}$.

\section{CONCLUSION}

Osteoporotic compression fracture of the spine may have a negative impact on the quality of life of geriatric patients. There are many choices of treatment available ${ }^{2,3}$. In selected patients with this injury, the procedure of posterior instrumentation and transpedicular bone grafting gives satisfactory results in terms of pain relief, some improvement in daily functionality as well as radiological correction of the deformity. However, this results should be studied for a longer follow up to confirm efficacy. 


\section{REFERENCES}

1. Goh LH, Tan SB, Liaw JS. Advances in surgical treatment of osteoporotic fractures of the spine. Ann Acad Med Singapore. 2002; 31(5): 623-30.

2. Kim DH, Vaccaro AR. Osteoporotic compression fractures of the spine; current options and considerations for treatment. Spine $J$ 2006; 6: 479-87.

3. Chotigavanich C, Sanpakit S, Wantthanapisith T, Thanapipatsiri S, Chotigavanich C. The surgical treatment of the osteoporotic vertebral compression fracture in the elderly patients with the spinal instrumentation. J Med Assoc Thai 2009; 92(15): 109-15

4. Schnitzler CM. Histomorphology of osteoporosis, in An's Orthopaedics Issues in Osteoporosis, Florida, USA: CRC press 2003: 19-37.

5. Halvorson TL, Kelley LA, Thomas KA, Whitecloud TS 3rd, Cook SD. Effects of bone mineral density on pedicle screw fixation. Spine 1994; 19(21): 2415-20.

6. Benzel EC. Implant-Bone Interfaces, in Biomechanics of Spine Stabilization, American Association of Neurologic Surgeons, Rolling Meadows, IL, 2001: 155.

7. Hu S. Internal Fixation in the Osteoporotic Spine. Spine 1997; 22(24): 43-8.

8. Daniaux H. Transpedicular Repositioning and Spongiosaplasty in Fracture of the Vertebral Bodies of the Lower Thoracic and Lumbar spine. Unfallchirurg 1986; 89(5): 197-213.

9. Ferara LA, McCormick WE. Biomechanics of Interbody Fusion in Osteoporotic Spine, in An's Orthopaedics Issues in Osteoporosis, Florida, USA: CRC Press, 2003: 371-82.

10. Moon MS, Choi WT. Stabilization of Fractured Thoracic and Lumbar Spine with Cotrel-Dubousset instrument. J Orthop Surg 2003; 11(1): 59-66.

11. Chiba M, McLain RF. Short Segment Pedicle Instrumentation: Biomechanical Analysis of Supplemental Hook Fixation. Spine 1996; 21(3): 288-94.

12. Hasegawa K, Takahashi HE. An Experimental Study of a Combination Method Using a Pedicle Screw and Laminar Hook for the Osteoporotic Spine. Spine 1997; 22(9): 958-62.

13. Gotzen L, Junge A, Koppelberg T, Stiletto R. Progress in Internal Fixator Stabilization of Thoracolumbar Spine Fractures. Unfallchirurg 1995; 98(2): 79-86.

14. Liljenqvist U, Mommsen U. Surgical Treatment of Thoracolumbar Spinal Fractures with Internal Fixator and Transpedicular Spongiosa-plasty. Unfallchirurgie 1995; 21(1): 30-9.

15. Grados F, Depriester C, Cayrolle G, Hardy N, Deramond H, Fardellone P. Long-term observations of osteoporotic fractures treated by percutaneous Vertebroplasty. Rheumatol 2000; 39(12): 1410-4

16. Yu SW, Lee PC, Ma CH, Chuang TY, Chen YJ. Vertebroplasty for the Treatment of Osteoporotic Compression Spinal Fracture: Comparison of Remedial Action at Different Stages of Injury. J Trauma 2004; 56(3): 629-32. 